\title{
Three sympatrically occurring species of Metarhizium show plant rhizosphere specificity
}

\begin{abstract}
Correspondence
Michael J. Bidochka

bidochka@brocku.ca
\end{abstract}

Received 4 May 2011

Revised 18 July 2011

Accepted 19 July 2011

\author{
Michael Wyrebek, Cristina Huber, Ramanpreet Kaur Sasan \\ and Michael J. Bidochka
}

\author{
Department of Biological Sciences, Brock University, 500 Glenridge Avenue, St Catharines, \\ ON L2S 3A1, Canada
}

\begin{abstract}
Here we tested the hypothesis that species of the soil-inhabiting insect-pathogenic fungus Metarhizium are not randomly distributed in soils but show plant-rhizosphere-specific associations. We isolated Metarhizium from plant roots at two sites in Ontario, Canada, sequenced the 5' EF-1 $\alpha$ gene to discern Metarhizium species, and developed an RFLP test for rapid species identification. Results indicated a non-random association of three Metarhizium species (Metarhizium robertsii, Metarhizium brunneum and Metarhizium guizhouense) with the rhizosphere of certain types of plant species (identified to species and categorized as grasses, wildflowers, shrubs and trees). M. robertsii was the only species that was found associated with grass roots, suggesting a possible exclusion of $M$. brunneum and M. guizhouense. Supporting this, in vitro experiments showed that $M$. robertsii conidia germinated significantly better in Panicum virgatum (switchgrass) root exudate than did M. brunneum or M. guizhouense. M. guizhouense and $M$. brunneum only associated with wildflower rhizosphere when co-occurring with $M$. robertsii. With the exception of these co-occurrences, M. guizhouense was found to associate exclusively with the rhizosphere of tree species, predominantly Acer saccharum (sugar maple), while M. brunneum was found to associate exclusively with the rhizosphere of shrubs and trees. These associations demonstrate that different species of Metarhizium associate with specific plant types.
\end{abstract}

\section{INTRODUCTION}

Metarhizium is an insect-pathogenic fungus currently used as a biological control agent against various insect species (Lomer et al., 1997, 2001; Milner \& Pereira, 2000; Hunter et al., 2001; Maniania et al., 2003; Shah \& Pell, 2003). Recent studies suggest that another ecological role of this fungus is as a plant rhizosphere associate. A green fluorescent protein (GFP)-expressing Metarhizium applied in an agricultural setting was not randomly distributed in the soil but showed preferential association with the plant rhizosphere (Hu \& St Leger, 2002). The rhizosphere has been identified as a potential reservoir for Metarhizium, with propagules persisting in the inner rhizosphere and decreasing over time in bulk soil (Hu \& St Leger, 2002). Furthermore, populations of Metarhizium have been shown to increase significantly over time within the

The GenBank/EMBL/DDBJ accession numbers for the 5 ' EF- $1 \alpha$ sequences of Metarhizium isolates are HM748301 (HKB1-1b), HM748302 (B18-ai), HM748303 (M31-ai), HM748304 (G90-bi), HM748305 (G55-ai), HM748307 (B77-ai), HM748308 (B34-aiii) and HM748309 (B35-avi).

A supplementary figure, showing RFLP analysis of $n t /$ and $p r 1$ using Rsal for isolates of Metarhizium, is available with the online version of this paper. rhizosphere (Bruck, 2005). Also, a plant adhesin (MAD2) has been shown to enable attachment to plants (Wang \& St Leger, 2007).

Notably, Metarhizium is phylogenetically related to the fungal grass endosymbionts Claviceps and Epichloë (Spatafora et al., 2007), suggesting a possible origin of plant association in Metarhizium. In a recent review article, Bruck (2010) suggested that rhizosphere competence in insect-pathogenic fungi was dependent upon the host plant. Additionally, Vega et al. (2009) suggested that future research on entomopathogenic fungi should concentrate on understanding the ecology of the fungi, focusing on roles such as rhizosphere colonization, in order to use them more effectively. The use of Metarhizium as a biocontrol agent has mostly fixated on its ability to kill insects, with little consideration of plant associations or rhizosphere ecology, thus limiting our ability to fully exploit this fungus for biocontrol efforts.

A common paradigm in insect pathology suggests that the host insect is the predominant influence on the population genetics of insect-pathogenic fungi. As such, the population genetics of Metarhizium has been assumed to be influenced primarily by host insect taxa (Riba et al., 1986; St Leger et al., 1992; Bridge et al., 1993, 1997; Fegan et al., 
1993; Leal et al., 1994, 1997; Tigano-Milani et al., 1995). However, this paradigm is being challenged. For example, in Ontario, the fungus previously known as Metarhizium anisopliae was found to comprise two cryptic species, namely Ontario group 1 (OG1) and Ontario group 2 (OG2) (Bidochka et al., 2001, 2005). These genetically distinctive, non-recombining groups were found to be strongly associated with habitat type, with isolates from agricultural/open field habitats belonging predominantly to OG1, and OG2 isolates found in forested soils. Interestingly, no differences in insect host specificity or virulence were found between these groups (Bidochka et al., 2001, 2005).

Here we further explored the 'habitat hypothesis' (i.e. agricultural/open fields or forests) in defining the distribution of Metarhizium species (Bidochka et al., 2001) and suggest that Metarhizium species show plant-specific rhizosphere associations within a habitat. Our objectives were to randomly collect plant root samples along a linear transect from an agricultural/open field habitat through to a forested habitat, at two independent sites, and to isolate and identify the Metarhizium species associated with these plant roots. Metarhizium was isolated from plant roots using a selective agar, and the $5^{\prime} \mathrm{EF}-1 \alpha$ gene was sequenced in a selection of isolates and compared with previously deposited nucleotide sequences for confirmation of Metarhizium species (Bischoff et al., 2009). The genus Metarhizium has recently been subdivided into different species according to the sequences of several genes (Bischoff et al., 2009). The sequence for the $5^{\prime}$ region of EF- $1 \alpha$ was deemed to be a diagnostic marker for Metarhizium species identification (Bischoff et al., 2009). We assessed the sequence data and designed an RFLP analysis of $5^{\prime} \mathrm{EF}-1 \alpha$ in order to rapidly identify, at the Metarhizium species level, a large number of isolates. We also utilized EF- $1 \alpha$ to identify Metarhizium species for representative isolates that we had previously referred to as OG1 and OG2.

\section{METHODS}

Root sample collection. A site near Brock University (St Catharines, ON), as well as a site in Guelph, ON, were selected using a geographical information system (GIS) (Google Earth). Locations were chosen that had a large, established forest area adjacent to a large open field with a strong delineation between habitats. The Brock site $\left(43^{\circ} 06^{\prime} 50.95^{\prime \prime} \mathrm{N} 79^{\circ} 14^{\prime} 53.21^{\prime \prime} \mathrm{W}\right)$ forest was mature and contained mostly maple, ash and beech, with the open field dominated by goldenrod species. The mature forest at the Guelph site $\left(43^{\circ} 29^{\prime} 34.34^{\prime \prime} \mathrm{N} 80^{\circ} 13^{\prime} 33.57^{\prime \prime} \mathrm{W}\right)$ contained mostly cedar, ash and maple, while the open field consisted of aster, goldenrod and wild carrot. Digital photographs of the sites are available from the authors upon request.

One hundred plant root samples were randomly collected approximately every metre along a linear transect that ran from the field to the forest, with the first 50 samples primarily from field plants, including grasses and wildflowers, and the last 50 predominantly from forest plants, trees and shrubs. Plant roots were dug out with a spade and excess soil was tapped from the roots before storage in separate, pre-labelled plastic reclosable bags. For mature trees and larger shrubs, fibrous roots found between the larger woody roots were collected. Additionally, representative foliage from each plant was photographed and collected in a pre-labelled envelope and was used to identify plant species using botanical keys and appropriate field guides.

Metarhizium isolation. Roots were washed with sterile distilled water to remove excess soil. Soil that adhered closely to the root was kept as representative of the rhizosphere. The roots were cut into $0.5 \mathrm{~cm}$ pieces, placed in $5 \mathrm{ml}$ distilled water and homogenized using a rotary homogenizer (Greiner Scientific). Samples $(100 \mu \mathrm{l})$ of homogenate were spread, in duplicate, onto selective media, containing 39 g potato-dextrose agar (PDA) $1^{-1}$ (Difco), 0.5 g cycloheximide $\mathrm{l}^{-1}$, $0.2 \mathrm{~g}$ chloramphenicol $\mathrm{l}^{-1}, 0.5 \mathrm{~g} 65 \%$ dodine $1^{-1}$ and $0.01 \mathrm{~g}$ crystal violet $1^{-1}$. The plates were incubated at $27^{\circ} \mathrm{C}$ for 20 days. Metarhizium isolates were identified by colony morphology, namely white mycelia with green conidia, as well as microscopic identification of conidial morphology. Morphologically differing colonies were individually isolated from the selective plate of each plant root sample and grown on PDA plates at $27{ }^{\circ} \mathrm{C}$ for 10 days. Morphologically similar colonies were also isolated multiple times from the same plant root sample.

Isolates HKB1-1b and 43a-2i (Bidochka et al., 2001) were used as representative isolates of OG1 and OG2, respectively. 43a-2i has been previously identified as M. brunneum and accessioned as ARSEF 8680 (Bischoff et al., 2009). ARSEF 2575 is the ex-type for M. robertsii (Bischoff et al., 2009).

The construction of GFP expressing plasmids, transformation, and creation of transgenic fungal lines were performed as previously described (Fang et al., 2006) in order to produce a GFP-expressing transformant of ARSEF 2575 ( $M$. robertsii). The transformant did not show any differences in growth, insect virulence or colony morphology in comparison to the wild-type.

DNA extraction. Morphologically different isolates were inoculated into $50 \mathrm{ml} 0.2 \%(\mathrm{w} / \mathrm{v})$ yeast extract, $1 \%$ peptone, $2 \%$ glucose broth (YPD) in flasks. The flasks were shaken at 200 r.p.m. at $27{ }^{\circ} \mathrm{C}$ for $3-$ 4 days. The mycelia were removed by vacuum filtration onto Fisherbrand P8 filter paper and washed with distilled water. The samples were then crushed in liquid nitrogen using a mortar and pestle, and DNA was extracted using either a DNeasy Plant Mini kit (Qiagen) or a Plant/Fungi DNA Isolation kit (Norgen).

PCR amplification and RFLP analysis. The subtilisin-like protease 1 (prl) and neutral trehalase $(n t l)$ genes were amplified for all isolates according to previously described conditions and digested with RsaI as previously described (Leal et al., 1997; Bidochka et al., 2001; Small et al., 2004). Each isolate was identified as belonging to either OG1 or OG2 based on RFLP banding pattern (Bidochka et al., 2001; Small et al., 2004).

The 5 ' region of the EF- $1 \alpha$ gene was also amplified according to previously described conditions (Rehner \& Buckley, 2005; Bischoff et al., 2006, 2009). 5' EF- $1 \alpha$ products were sequenced for five isolates of OG1 and two isolates from each of the possible genetic groups present in OG2, including representative isolates HKB1-1b (OG1), 43a-2i (OG2) and ARSEF 2575 (OG1). Putatively unique nucleotide polymorphisms were identified for the $5^{\prime} \mathrm{EF}-1 \alpha$ product of each species, and restriction site analysis of the $5^{\prime}$ EF- $1 \alpha$ sequences revealed that Ontario isolates could be differentiated based on RFLP banding patterns of the 5' EF- $1 \alpha$ amplification product double digested with MseI and XhoI. This was performed in a total volume of $20 \mu$ l, which included $5 \mu \mathrm{l} 5^{\prime}$ EF- $1 \alpha$ PCR product, $2 \mu \mathrm{l} 10 \times$ NE Buffer 4 (NEB), $4 \mu \mathrm{l} 10 \times \mathrm{BSA}, 10$ units MseI (NEB) and 20 units XhoI (NEB). Reactions were incubated at $37{ }^{\circ} \mathrm{C}$ for $16 \mathrm{~h}$. 
All amplified DNA sequences and RFLP products were visualized by electrophoresis on a $1 \%$ agarose gel, run at $70 \mathrm{~V}$ for $45 \mathrm{~min}$ in $0.5 \times$ TBE buffer.

Sequencing. Prior to sequencing, DNA samples were purified using a QIAquick PCR Purification kit (Qiagen). The 5' EF- $1 \alpha$ PCR products were sent to the core molecular biology lab at York University, ON, for sequencing.

Phylogenetic identification of Metarhizium isolates Molecular phylogenetic analysis of the $5^{\prime} \mathrm{EF}-1 \alpha$ sequences was conducted in order to identify the Metarhizium species of sequenced isolates. Alignments were made with CLUSTAL_X 2.1 (Larkin et al., 2007) using the default settings. A maximum-parsimony phylogenetic tree was constructed using PHYLIP 3.69 (Felsenstein, 2009). Non-parametric bootstrapping was conducted using 1000 pseudoreplicates, with 10 random addition replicates per parsimony run and subtree pruning and regrafting (SPR) branch swapping.

Seed sterilization, conidial inoculation and microscopy. Phaseolus vulgaris (haricot bean) and Panicum virgatum (switchgrass) seeds were surface-sterilized using a modification of the method of Miché \& Balandreau (2001). First, seeds were immersed in sterile distilled water for $30 \mathrm{~min}$. The seeds were then immersed in $4 \%$ sodium hypochlorite solution for $2.5 \mathrm{~h}$. The fluid was decanted and the seeds were washed with sterile distilled water. The seeds were then immersed in $15 \%$ hydrogen peroxide for $30 \mathrm{~min}$ followed by washing three times with sterile distilled water. Sterilized seeds were kept at $4{ }^{\circ} \mathrm{C}$ overnight to allow for synchronization of growth. Switchgrass seeds were immersed in an inoculum of $10^{7}$ spores $\mathrm{ml}^{-1}$ of GFPexpressing Metarhizium (ARSEF 2575) for $1 \mathrm{~h}$, plated in sterile soil, and kept at $25{ }^{\circ} \mathrm{C}$ for 14 days with a photoperiod of $12 \mathrm{~h}$. For haricot bean, sterilized seeds were allowed to develop into seedlings, and then inoculated. The treated bean roots were kept at $25{ }^{\circ} \mathrm{C}$ for 14 days with a photoperiod of $12 \mathrm{~h}$. Sterile water was added regularly to avoid drying of the samples.

Roots were rinsed with sterile distilled water without a fixing reagent. A Leica DM RBE laser scanning confocal microscope equipped with an argon/krypton laser was used for the observation of GFPexpressing Metarhizium on roots.

Root exudate collection. Surface-sterilized switchgrass seeds were soaked in water in Petri dishes, kept on an orbital shaker and provided with light. Once $90 \%$ of the seeds had germinated, samples were kept on the shaker for an additional 4 days, after which root exudate was collected by vacuum filtration.

Conidial germination assay. Conidial suspensions $\left(10^{7}\right.$ conidia $\mathrm{ml}^{-1}$ ) of ARSEF 2575 (M. robertsii), 43a-2i (M. brunneum) and B77ai (M. guizhouense) were inoculated $(1 \% \mathrm{v} / \mathrm{v})$ into switchgrass root exudate and incubated at $15{ }^{\circ} \mathrm{C}$ or $27{ }^{\circ} \mathrm{C}$. Positive controls for conidial germination were also done in YPD. Conidial germination was assessed microscopically (Leitz DIAPLAN light microscope) at 12,24 and $48 \mathrm{~h}$.

\section{RESULTS}

\section{Metarhizium species in the sampling sites}

After plant root samples were collected, the Metarhizium colonies were isolated and DNA was extracted, RFLP analysis of $n t l$ was initially used to assign each isolate to OG1 or OG2 (see Supplementary Fig. S1A, available with the online version of this paper). RFLP analysis of the pr1 gene showed that isolates assigned to OG2, based on RFLP analysis of $n t l$, displayed two possible banding patterns for prl, which suggested the presence of two distinct genetic groups within OG2 (Supplementary Fig. S1B).

In order to resolve the exact species composition of each of these distinct genetic groups, the $5^{\prime}$ region of EF- $1 \alpha$ was amplified and sequenced for four isolates of OG1 and two isolates from each of the possible genetic groups present in OG2, including representative isolates HKB1-1b (OG1), 43a-2i (OG2) and ARSEF 2575 (OG1). Using molecular phylogenetic identification, isolates initially assigned to OG1 were identified as $M$. robertsii (Fig. 1). OG2 was determined to comprise two species, namely $M$. brunneum and M. guizhouense (Fig. 1).

Restriction enzymes MseI and XhoI were used to cleave amplified portions of the $5^{\prime} \mathrm{EF}-1 \alpha$ gene, which resulted in RFLP patterns that differentiated Ontario isolates of Metarhizium (Fig. 2). All species displayed a distinct RFLP pattern, with the exception of the M. brunneum isolates, for which two distinct RFLP patterns were identified while screening isolates. Sequence analysis of the 5' EF- $1 \alpha$ gene for another M. brunneum RFLP pattern showed six single-nucleotide polymorphisms, including one within an MseI site, resulting in a polymorphic RFLP pattern. This alternate M. brunneum $5^{\prime}$ EF- $1 \alpha$ gene shared $99.2 \%$ identity with the other M. brunneum $5^{\prime}$ EF- $1 \alpha$ sequence (705/711 bp).

Using this RFLP analysis, screening of all isolates collected demonstrated that $M$. robertsii is the most prevalent species of Metarhizium in the two sampling sites in Ontario (Fig. 3), with 49 and 32 isolates collected from the Guelph and Brock sites, respectively. M. brunneum was also present at

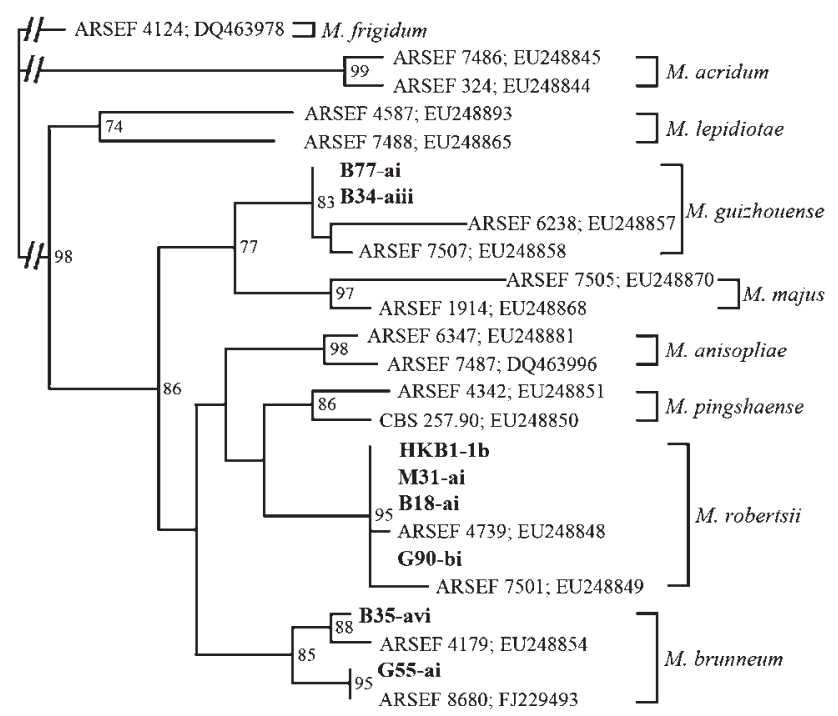

Fig. 1. Maximum-parsimony phylogenetic tree of $5^{\prime} \mathrm{EF}-1 \alpha$ sequences of Metarhizium isolates. Bootstrap values are based on 1000 pseudoreplicates; values $>70 \%$ are shown. 


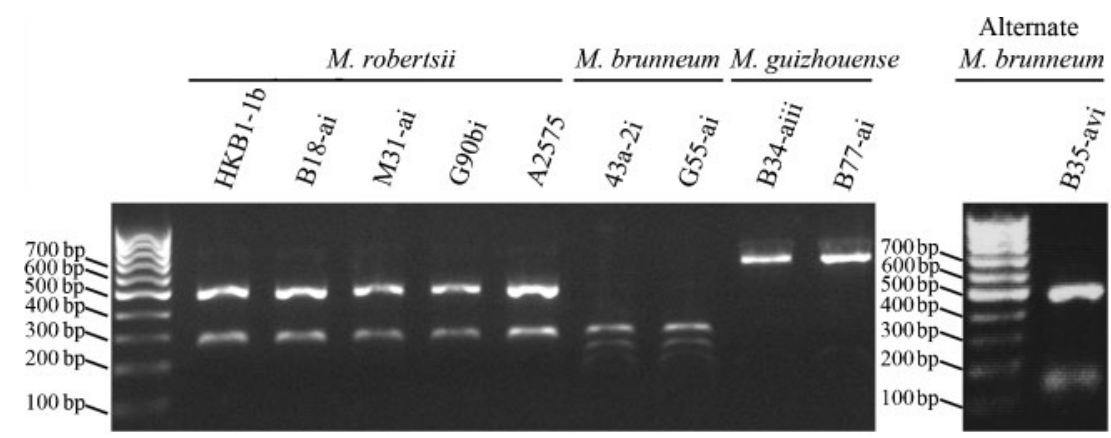

Fig. 2. RFLP analysis of $5^{\prime} \mathrm{EF}-1 \alpha$ using Msel and Xhol for Metarhizium isolates.

both sites, but at lower frequency, with 13 and 2 isolates collected from the Guelph and Brock sites, respectively. Interestingly, M. guizhouense was only isolated from the Brock site, with 11 isolates collected, but not at the Guelph site. Morphologically similar isolates from the same plant root sample were always identified as the same species, and thus were only counted as a single isolate.

\section{Plant-specific associations}

Of all 200 plant root samples collected, 102 (51\%) resulted in isolations of Metarhizium. Metarhizium was found to associate with $63 \%, 62 \%, 55 \%$ and $35 \%$ of grass, wildflower, shrub and tree root samples, respectively. Generally, Metarhizium was found most abundantly from wildflower species.

Three species of Metarhizium were isolated from the rhizosphere of plant root samples collected during this study, namely $M$. robertsii, $M$. brunneum and $M$. guizhouense. After identifying the species of Metarhizium isolates collected, an association between Metarhizium species and habitat was observed (Fig. 3), confirming previous results (Bidochka et al., 2001). That is, M. robertsii was found predominantly in the agricultural or open field habitats, while M. brunneum and M. guizhouense (at the Brock Site) were found predominantly in the forested habitats.

Additionally, it was found that within these habitats, the three species of Metarhizium associated with specific plant types (Fig. 3). There were significant associations of Metarhizium species with plant type at the Brock and Guelph sites (Yates' $\chi^{2}=19.808, P<0.005$ and $\chi^{2}=21.192$, $P<0.001$, respectively). Notably, $M$. robertsii was the only species isolated from grasses. It was also commonly isolated from wildflowers. It is also notable that M. brunneum and $M$. guizhouense were only isolated from wildflowers when $M$. robertsii was also isolated from that same plant root sample.

With the exception of one co-occurrence with $M$. robertsii on the wildflower Solidago altissima (late goldenrod), $M$. guizhouense was isolated exclusively from trees, suggesting a specific association with this plant type. Additionally, it was observed that M. guizhouense was predominantly isolated from species of the Acer (maple) genus, primarily Acer saccharum (sugar maple) (Fig. 3). Of the 11 different occurrences of M. guizhouense at the Brock site, seven were isolated from trees of the genus Acer. Six of these were from A. saccharum and one was from Acer nigrum (black maple). At the Guelph site, three A. nigrum and one Acer saccharinum (silver maple) roots were sampled, from which a single $M$. brunneum isolate was obtained from A. nigrum (Fig. 3). Additionally, M. guizhouense was the only species to be isolated from root samples of Fraxinus americana (white ash), with one of nine samples at the Brock site resulting in isolations of this species. Neither of two ash root samples at the Guelph site had M. guizhouense (Fig. 3).

M. brunneum was uncommon at the Brock site and was isolated on its own from one tree, Fagus grandifolia (American beech). It was also found to co-occur with $M$. robertsii on the wildflower Barbarea vulgaris (wintercress). At the Guelph site, M. brunneum was isolated exclusively from shrub and tree species, with the exception of one cooccurrence with $M$. robertsii on the wildflower Trifolium hybridum (alsike clover) (Fig. 3). M. brunneum was also found to co-occur with $M$. robertsii on the shrub Cornus alternifolia (alternate-leaved dogwood) and the tree Betula alleghaniensis (yellow birch). Additionally, M. brunneum was the only species to be isolated from root samples of Thuja occidentalis (eastern white cedar), with three of 11 samples at the Guelph site resulting in isolations of this species.

\section{In vitro microscopy}

In vitro experiments demonstrated the close association of a GFP-expressing Metarhizium isolate (ARSEF 2575) with Phaseolus vulgaris (haricot bean) root (Fig. 4a) and Panicum virgatum (switchgrass) root (Fig. 4b). Hyphae can be seen growing on the root surfaces, as well as around the root hairs in switchgrass. Plants appeared healthy even after long-term (up to 20 days) root colonization by Metarhizium.

\section{Conidial germination assays}

The level of conidial germination in switchgrass root exudate was monitored over $48 \mathrm{~h}$ for an isolate of each 


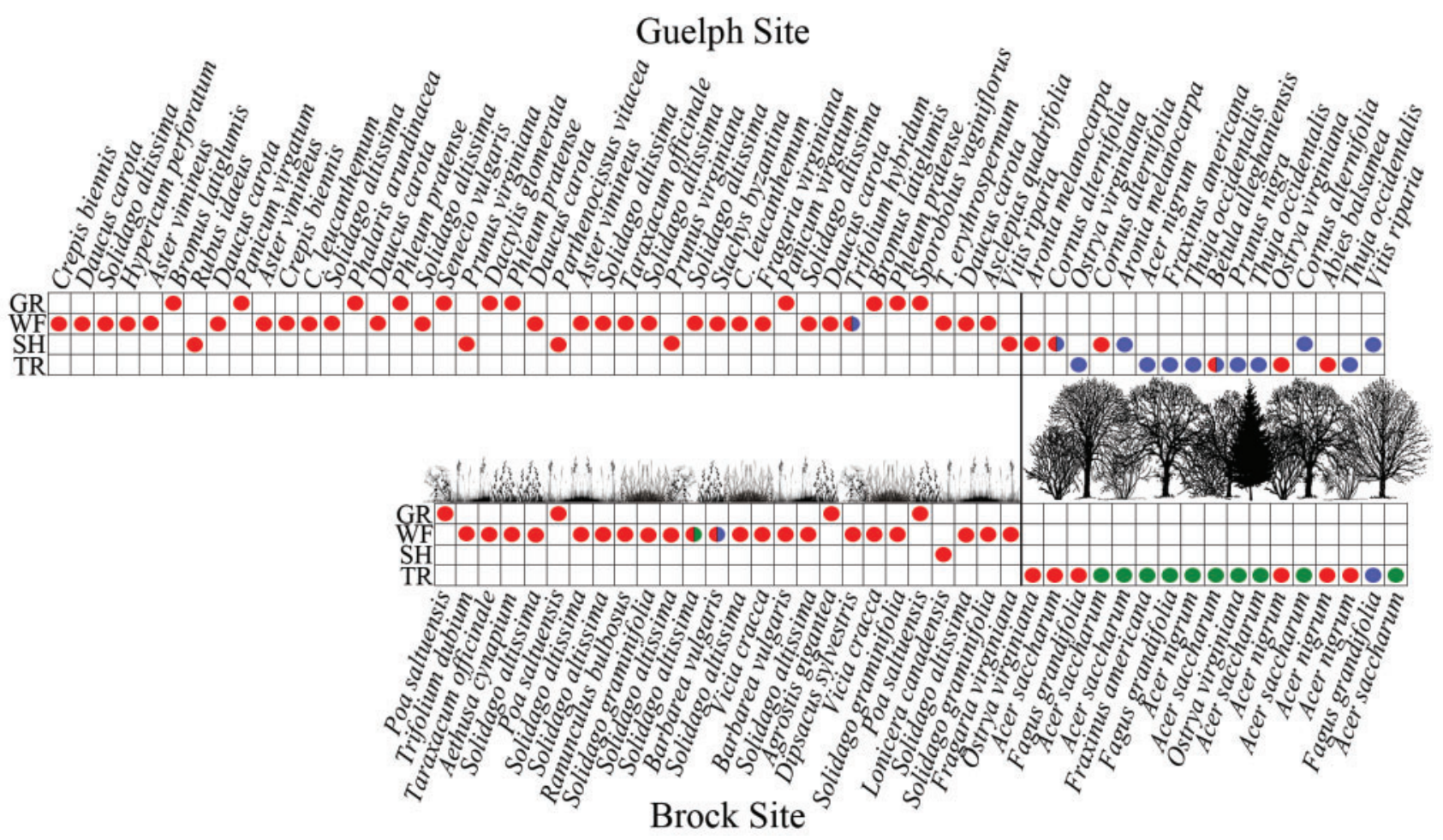

Fig. 3. Plant species, plant type (GR, grass; WF, wildflower; $\mathrm{SH}$, shrub; TR, tree) and Metarhizium species (red, M. robertsii; blue, M. brunneum; green, M. guizhouense) isolated from plant root samples collected at the Guelph and Brock sites. Samples on the left represent transect samples in the agricultural forage field, and samples on the right represent the transect samples in a forest. Plant root samples collected resulting in no Metarhizium isolations were as follows. Guelph: GR - Phalaris arundinacea, Agrostis perennans; WF - Cirsium arvense, Convolvulus arvensis, Solidago altissima (2), Aster vimineus, Daucus carota, Thaspium trifoliatum; SH - Rubus idaeus, Salix bebbiana, Aronia melanocarpa (2), Parthenocissus vitacea, Frangula alnus; TR - Thuja occidentalis (8), Abies balsamea (5), Fraxinus americana (2), Acer saccharinum, Tsuga canadensis (2), Betula alleghaniensis (3), Acer nigrum (2), Fraxinus nigra, Prunus nigra, Ostrya virginiana. Brock: GR - Poa saltuensis (4), Schizanchne purpurascens, Glyceria canadensis, Agrostis gigantean; WF- Solidago altissima (3), Dipsacus sylvestris (4), Daucus carota (3), Barbarea vulgaris (3), Chrysanthemum leucanthemum, Hieracium pratense, Lepidium campestre, Solidago graminifolia (2), Petasites frigidus, Taraxacum officinale, Dalibarda repens, Plantago major; SH - Prunus virginiana (2), Cornus stolonifera, Sambucus racemosa subsp. pubens; TR - Acer saccharum (7), Fraxinus americana (8), Fagus grandifolia (6), Acer nigrum (2), Ostrya virginiana.

species: ARSEF 2575 (M. robertsii), 43a-2i (M. brunneum) and B77-ai (M. guizhouense) (Fig. 5). Differences in germination and hyphal growth were observed between the Metarhizium species grown in switchgrass root exudate, relative to growth in YPD as a positive control. M. robertsii demonstrated a high level of germination in the root exudate. A high level of hyphal growth was also seen after $24 \mathrm{~h}$. Additionally, the germination rate of $M$. robertsii conidia in switchgrass root exudate was higher than the rate in YPD after $48 \mathrm{~h}$ at $27{ }^{\circ} \mathrm{C}$ and $15^{\circ} \mathrm{C}$. Conversely, $M$. brunneum and M. guizhouense showed minimal germination in switchgrass root exudate, relative to YPD. Similar results were obtained at $27{ }^{\circ} \mathrm{C}$ and $15{ }^{\circ} \mathrm{C}$. The differences in relative rates of germination between $M$. robertsii, and $M$. brunneum or M. guizhouense were statistically significant at all time intervals $(12,24$ and $48 \mathrm{~h}$ ) and both temperatures $\left(27^{\circ} \mathrm{C}\right.$ and $\left.15{ }^{\circ} \mathrm{C}\right)(t$ tests $P \leqslant 0.0005)$. Conidia failed to germinate in water for all three species.

\section{DISCUSSION}

Here we identified three sympatrically occurring species of Metarhizium in Ontario that were associated with the rhizosphere of specific plant types. We suggest that plantrhizosphere-specific associations within a habitat determine the distribution of Metarhizium species. M. robertsii preferentially associated with grasses and wildflowers. $M$. brunneum preferentially associated with shrubs and trees, and M. guizhouense was isolated almost exclusively from trees, predominantly A. saccharum.

Field data demonstrated that $M$. robertsii is the most prevalent Metarhizium species in our two sampling sites in Ontario (Fig. 3), a finding supported by bulk soil sampling (Bidochka et al., 2001). There may be some selective advantage to this species, which may not be due to superior virulence or ability to infect a host (Bidochka et al., 2001), but rather to an ecological ability to survive or inhabit a 

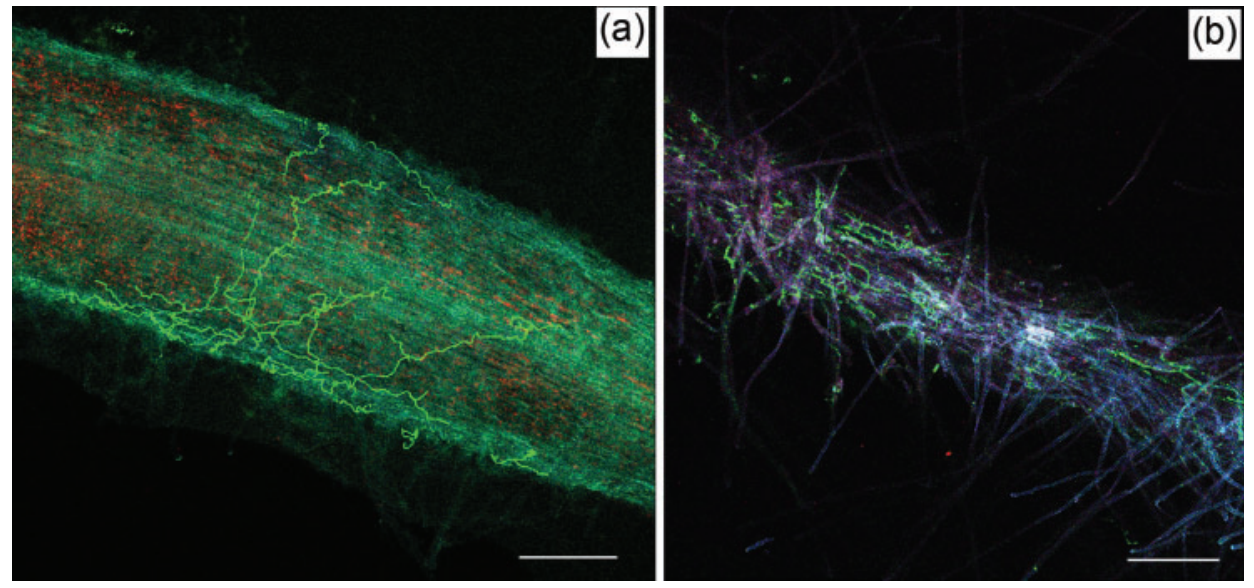

Fig. 4. Confocal images of a GFP-expressing Metarhizium (ARSEF 2575) associating with Phaseolus vulgaris (haricot bean) root (a) and Panicum virgatum (switchgrass) root (b). Scale bars, $200 \mu \mathrm{m}$.

certain plant rhizosphere. Moreover, this ecological ability may be mechanistically unrelated to pathogenicity, as Ontario species have demonstrated no significant differences in host specificity or virulence. A similar hypothesis has been proposed for the plant pathogen Fusarium graminearum, in which one lineage was found to be more prevalent than others, while all lineages had similar pathogenicity (Lee et al., 2009).

In addition to being the most prevalent species found in Ontario soils, M. robertsii also demonstrated an ability to

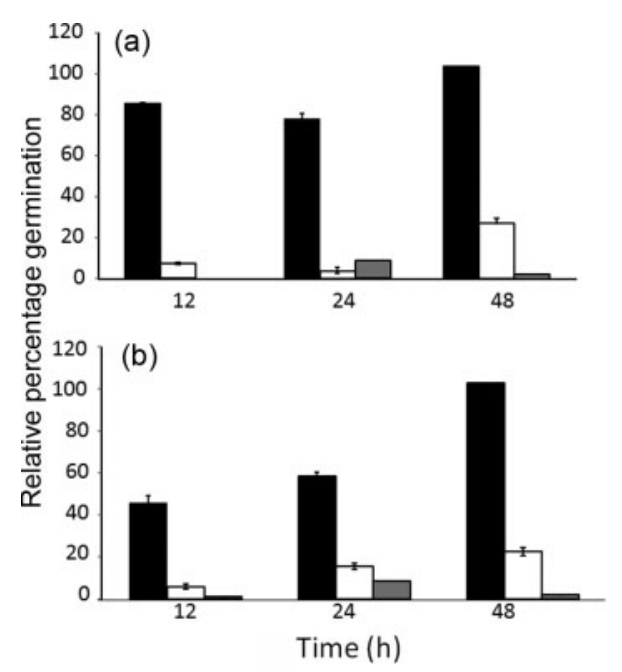

Fig. 5. Relative germination rates of $M$. robertsii (black bars), $M$. brunneum (white bars) and M. guizhouense (grey bars) conidia inoculated into Panicum virgatum (switchgrass) root exudate at $27^{\circ} \mathrm{C}(\mathrm{a})$ and $15{ }^{\circ} \mathrm{C}(\mathrm{b})$. Germination rates were relative to YPD as the positive control. Conidia failed to germinate in water for all three species. Germination was scored from 100 conidia; means \pm SD are shown $(n=3)$. The experiment was repeated twice with similar results. associate with a wider range of plant types and species (Fig. $3)$. In particular, $M$. robertsii was prevalent among wildflower species and was the only species of Metarhizium to associate with wildflowers on its own. On the other hand, $M$. brunneum and M. guizhouense were only found to associate with wildflowers when in conjunction with $M$. robertsii. The exact nature and mechanisms of these associations are unknown, and there is a paucity of research conducted on plant associations of similar rhizosphere-competent fungi. However, examples of specific mycorrhizal associations are known. Synergistic colonization has been suggested in arbuscular mycorrhizal fungi, in which Gigaspora rosea and Scutellospora castanea colonization was significantly increased in the presence of Glomus species, particularly Glomus mosseae (van Tuinen et al., 1998). In the case of $S$. castanea, when inoculated on its own, root colonization frequency was zero after 8 weeks, but increased to approximately $35 \%$ in the presence of Glomus species.

While $M$. robertsii was found to co-occur in the rhizosphere with other Metarhizium species, M. brunneum and $M$. guizhouense were never isolated from the rhizosphere of the same plant. There may be competition between $M$. brunneum and $M$. guizhouense, wherein one species outcompetes the other with respect to root colonization. In the ectomycorrhizal fungus Rhizopogon, the timing of colonization, as well as the proportion of the root system colonized, are key factors in competitive success (Kennedy et al., 2009). In arbuscular mycorrhizal fungi, colonization of a plant by one fungus has been shown to alter root exudation, which may inhibit development of subsequent mycorrhizal interactions (Pinior et al., 1999; Vierheilig et al., 2003).

Host plant specificity has been suggested to be responsible for differences in ectomycorrhizal community composition and diversity (Molina et al., 1992; Kernaghan et al., 2003). This finding may have implications in Metarhizium colonization of the plant rhizosphere, where we found that this is not a loose association but rather that 
Metarhizium is attracted to and associates intimately with root surfaces (Fig. 4). In the field, $M$. robertsii was the only species found to associate with grass roots. Additionally, the in vitro conidial germination experiments demonstrated that switchgrass root exudate was a favourable medium for germination of $M$. robertsii conidia compared with M. brunneum or M. guizhouense (Fig. 5).

The in vitro experiments complement the field data and demonstrate that this exclusion is a plant-associated effect, rather than an artefact of the habitat association or due to a specific insect host. While the mechanism for this exclusion is unknown, it may be due to compounds in the grass root exudate. Phenolics, and other compounds such as isothiocyanates, have been implicated in the inhibition of root colonization by some fungi (Piotrowski et al., 2008; Wolfe et al., 2008; Bainard et al., 2009). Grass species may exude a compound that is toxic or inhibitory to the growth of $M$. brunneum and M. guizhouense. Alternately, M. brunneum (Guelph site) was isolated from T. occidentalis, and $M$. guizhouense was isolated from Fraxinus americana, to the exclusion of other Metarhizium species. The associations observed in this study are unlikely to be due to chance alone, and indicate specific rhizosphere associations.

Specific rhizosphere associations have been noted in the ectomycorrhizal fungi Tuber borchii, Tuber melanosporum and Lactarius quietus (Courty et al., 2008; Martin \& Nehls, 2009). Conversely, arbuscular mycorrhizal fungi are largely not hostspecific (Klironomos, 2000). In most instances, these associations have been shown to be beneficial to the host plant, and are critical for nutrient cycling in sustainable ecosystems (Estrada-Luna et al., 2000; Rai et al., 2001; Sirrenberg et al., 2007; Felten et al., 2009; Martin \& Nehls, 2009; Baldi et al., 2010). Specific rhizosphere associations, with respect to rhizosphere competence, have also been demonstrated in Metarhizium, wherein certain isolates are only rhizospherecompetent with certain plants (Bruck, 2010).

Our findings of plant-rhizosphere-specific associations in Metarhizium have significant implications for the use of Metarhizium as a biological control agent. The use of a rhizosphere-competent isolate of Metarhizium provided nearly $80 \%$ control against a target insect (Bruck, 2005). Plant-rhizosphere specificity must be taken into account in order to optimize delivery against a target insect and ensure sustainability in the plant rhizosphere.

\section{ACKNOWLEDGEMENTS}

This research was conducted with the assistance of an NSERC Discovery Grant to M. J. B.

\section{REFERENCES}

Bainard, L. D., Brown, P. D. \& Upadhyaya, M. K. (2009). Inhibitory effect of tall hedge mustard (Sisymbrium loeselii) allelochemicals on rangeland plants and arbuscular mycorrhizal fungi. Weed Sci 57, 386393.
Baldi, A., Farkya, S., Jain, A., Gupta, N., Mehra, R., Datta, V., Srivastava, A. K. \& Bisaria, V. S. (2010). Enhanced production of podophyllotoxins by co-culture of transformed Linum album cells with plant growth-promoting fungi. Pure Appl Chem 82, 227241.

Bidochka, M. J., Kamp, A. M., Lavender, T. M., Dekoning, J. \& De Croos, J. N. A. (2001). Habitat association in two genetic groups of the insect-pathogenic fungus Metarhizium anisopliae: uncovering cryptic species? Appl Environ Microbiol 67, 1335-1342.

Bidochka, M. J., Small, C. L. \& Spironello, M. (2005). Recombination within sympatric cryptic species of the insect pathogenic fungus Metarhizium anisopliae. Environ Microbiol 7, 1361-1368.

Bischoff, J. F., Rehner, S. A. \& Humber, R. A. (2006). Metarhizium frigidum sp. nov.: a cryptic species of $M$. anisopliae and a member of the M. flavoviride complex. Mycologia 98, 737-745.

Bischoff, J. F., Rehner, S. A. \& Humber, R. A. (2009). A multilocus phylogeny of the Metarhizium anisopliae lineage. Mycologia 101, 512530.

Bridge, P. D., Williams, M. A. J., Prior, C. \& Paterson, R. R. M. (1993). Morphological, biochemical and molecular characteristics of Metarhizium anisopliae and M. flavoviride. J Gen Microbiol 139, 1163-1169.

Bridge, P. D., Prior, C., Sagbohan, J., Lomer, C. J., Carey, M. \& Buddie, A. (1997). Molecular characterization of isolates of Metarhizium from locusts and grasshoppers. Biodivers Conserv 6, 177-189.

Bruck, D. J. (2005). Ecology of Metarhizium anisopliae in soilless potting media and the rhizosphere: implications for pest management. Biol Control 32, 155-163.

Bruck, D. J. (2010). Fungal entomopathogens in the rhizosphere. BioControl 55, 103-112.

Courty, P. E., Poletto, M., Duchaussoy, F., Buée, M., Garbaye, J. \& Martin, F. (2008). Gene transcription in Lactarius quietus-Quercus petraea ectomycorrhizas from a forest soil. Appl Environ Microbiol 74, 6598-6605.

Estrada-Luna, A. A., Davies, F. T., Jr \& Egilla, J. N. (2000). Mycorrhizal fungi enhancement of growth and gas exchange of micropropagated guava plantlets (Psidium guajava L.) during ex vitro acclimatization and plant establishment. Mycorrhiza 10, 1-8.

Fang, W., Pei, Y. \& Bidochka, M. J. (2006). Transformation of Metarhizium anisopliae mediated by Agrobacterium tumefaciens. Can J Microbiol 52, 623-626.

Fegan, M., Manners, J. M., Maclean, D. J., Irwin, J. A. G., Samuels, K. D. Z., Holdom, D. G. \& Li, D. P. (1993). Random amplified polymorphic DNA markers reveal a high degree of genetic diversity in the entomopathogenic fungus Metarhizium anisopliae var. anisopliae. J Gen Microbiol 139, 2075-2081.

Felsenstein, J. (2009). PHYLIP (phylogeny inference package) version 3.69. Distributed by the author. Department of Genome Sciences, University of Washington, Seattle, USA.

Felten, J., Kohler, A., Morin, E., Bhalerao, R. P., Palme, K., Martin, F., Ditengou, F. A. \& Legué, V. (2009). The ectomycorrhizal fungus Laccaria bicolor stimulates lateral root formation in poplar and Arabidopsis through auxin transport and signaling. Plant Physiol 151, 1991-2005.

Hu, G. \& St Leger, R. J. (2002). Field studies using a recombinant mycoinsecticide (Metarhizium anisopliae) reveal that it is rhizosphere competent. Appl Environ Microbiol 68, 6383-6387.

Hunter, D. M., Milner, R. J. \& Spurgin, P. A. (2001). Aerial treatment of the Australian plague locust, Chortoicetes terminifera (Orthoptera: Acrididae) with Metarhizium anisopliae (Deuteromycotina: Hyphomycetes). Bull Entomol Res 91, 93-99. 
Kennedy, P. G., Peay, K. G. \& Bruns, T. D. (2009). Root tip competition among ectomycorrhizal fungi: are priority effects a rule or an exception? Ecology 90, 2098-2107.

Kernaghan, G., Widden, P., Bergeron, Y., Legare, S. \& Pare, D. (2003). Biotic and abiotic factors affecting ectomycorrhizal diversity in boreal mixed-woods. Oikos 102, 497-504.

Klironomos, J. N. (2000). Host-specificity and functional diversity among arbuscular mycorrhizal fungi. In Microbial Biosystems: New Frontiers. Proceedings of the 8th International Symposium on Microbial Ecology, pp. 845-851. Edited by C. R. Bell, M. Brylinsky \& P. JohnsonGreen. Halifax, Canada: Atlantic Canada Society for Microbial Ecology.

Larkin, M. A., Blackshields, G., Brown, N. P., Chenna, R., McGettigan, P. A., McWilliam, H., Valentin, F., Wallace, I. M., Wilm, A. \& other authors (2007). CLUSTAL W and CLUSTAL_X version 2.0. Bioinformatics 23, 2947-2948.

Leal, S. C. M., Bertioli, D. J., Butt, T. M. \& Peberdy, J. F. (1994). Characterization of isolates of the entomopathogenic fungus Metarhizium anisopliae by RAPD-PCR. Mycol Res 98, 1077-1081.

Leal, S. C. M., Bertioli, D. J., Butt, T. M., Carder, J. H., Burrows, P. R. \& Peberdy, J. F. (1997). Amplification and restriction endonuclease digestion of the Pr1 gene for the detection and characterization of Metarhizium strains. Mycol Res 101, 257-265.

Lee, J., Chang, I. Y., Kim, H., Yun, S. H., Leslie, J. F. \& Lee, Y. W. (2009). Genetic diversity and fitness of Fusarium graminearum populations from rice in Korea. Appl Environ Microbiol 75, 3289-3295.

Lomer, C. J., Prior, C. \& Kooyman, C. (1997). Development of Metarhizium spp. for control of grasshoppers and locusts. Mem Entomol Soc Can 129, 265-286.

Lomer, C. J., Bateman, R. P., Johnson, D. L., Langewald, J. \& Thomas, M. (2001). Biological control of locusts and grasshoppers. Annu Rev Entomol 46, 667-702.

Maniania, N. K., Sithanantham, S., Ekesi, S., Ampong-Nyarko, K., Baumgartner, J., Lohr, B. \& Matoka, C. M. (2003). A field trial of the entomogenous fungus Metarhizium anisopliae for control of onion thrips, Thrips tabaci. Crop Prot 22, 553-559.

Martin, F. \& Nehls, U. (2009). Harnessing ectomycorrhizal genomics for ecological insights. Curr Opin Plant Biol 12, 508-515.

Miché, L. \& Balandreau, J. (2001). Effects of rice seed surface sterilization with hypochlorite on inoculated Burkholderia vietnamiensis. Appl Environ Microbiol 67, 3046-3052.

Milner, R. J. \& Pereira, R. M. (2000). Microbial control of urban pestcockroaches, ants and termites. In Field Manual of Techniques in Invertebrate Pathology, 1st edn. pp. 721-740. Edited by L. A. Lacey \& H. K. Kaya. Boston, USA: Kluwer Academic Publishers.

Molina, R., Massicotte, H. \& Trappe, J. M. (1992). Specificity phenomena in mycorrhizal symbioses: community-ecological consequences and practical implications. In Mycorrhizal Functioning, pp. 357-423. Edited by M. F. Allen. London, UK: Chapman \& Hall.

Pinior, A., Wyss, U., Piche, Y. \& Vierheilig, H. (1999). Plants colonized by AM fungi regulate further root colonization by AM fungi through altered root exudation. Can J Bot 77, 891-897.

Piotrowski, J. S., Morford, S. L. \& Rillig, M. C. (2008). Inhibition of colonization by a native arbuscular mycorrhizal fungal community via Populus trichocarpa litter, litter extract, and soluble phenolic compounds. Soil Biol Biochem 40, 709-717.

Rai, M., Acharya, D., Singh, A. \& Varma, A. (2001). Positive growth responses of the medicinal plants Spilanthes calva and Withania somnifera to inoculation by Piriformospora indica in a field trial. Mycorrhiza 11, 123-128.

Rehner, S. A. \& Buckley, E. (2005). A Beauveria phylogeny inferred from nuclear ITS and EF1- $\alpha$ sequences: evidence for cryptic diversification and links to Cordyceps teleomorphs. Mycologia 97, 84-98.

Riba, G., Bouvier-Fourcade, I. \& Caudal, A. (1986). Isoenzymes polymorphism in Metarhizium anisopliae (Deuteromycotina: Hyphomycetes) entomogenous fungi. Mycopathology 96, 161-169.

Shah, P. A. \& Pell, J. K. (2003). Entomopathogenic fungi as biological control agents. Appl Microbiol Biotechnol 61, 413-423.

Sirrenberg, A., Göbel, C., Grond, S., Czempinski, N., Ratzinger, A., Karlovsky, P., Santos, P., Feussner, I. \& Pawlowski, K. (2007). Piriformospora indica affects plant growth by auxin production. Physiol Plant 131, 581-589.

Small, C. L., Donaldson, N. \& Bidochka, M. J. (2004). Nucleotide sequence variation does not relate to differences in kinetic properties of neutral trehalase from the insect pathogenic fungus Metarhizium anisopliae. Curr Microbiol 48, 428-434.

Spatafora, J. W., Sung, G. H., Sung, J. M., Hywel-Jones, N. L. \& White, J. F., Jr (2007). Phylogenetic evidence for an animal pathogen origin of ergot and the grass endophytes. Mol Ecol 16, 1701-1711.

St Leger, R. J., May, B., Allee, L. L., Frank, D. C., Staples, R. C. \& Roberts, D. W. (1992). Genetic differences in allozymes and in formation of infection structures among isolates of the entomopathogenic fungus Metarhizium anisopliae. J Invertebr Pathol 60, 89-101.

Tigano-Milani, M. S., Gomes, A. C. M. M. \& Sobral, B. W. S. (1995). Genetic variability among Brazilian isolates of the entomopathogenic fungus Metarhizium anisopliae. J Invertebr Pathol 65, 206-210.

van Tuinen, D., Jacquot, E., Zhao, B., Gollotte, A. \& GianinazziPearson, V. (1998). Characterization of root colonization profiles by a microcosm community of arbuscular mycorrhizal fungi using 25S rDNA-targeted nested PCR. Mol Ecol 7, 879-887.

Vega, F. E., Goettel, M. S., Blackwell, M., Chandler, D., Jackson, M. A., Keller, S., Koike, M., Maniania, N. K., Monzon, A. \& Ownley, B. H. (2009). Fungal entomopathogens: new insights on their ecology. Fungal Ecol 2, 149-159.

Vierheilig, H., Lerat, S. \& Piché, Y. (2003). Systemic inhibition of arbuscular mycorrhiza development by root exudates of cucumber plants colonized by Glomus mosseae. Mycorrhiza 13, 167-170.

Wang, C. \& St Leger, R. J. (2007). The MAD1 adhesin of Metarhizium anisopliae links adhesion with blastospore production and virulence to insects, and the MAD2 adhesin enables attachment to plants. Eukaryot Cell 6, 808-816.

Wolfe, B. E., Rodgers, V. L., Stinson, K. A. \& Pringle, A. (2008). The invasive plant Alliaria petiolata (garlic mustard) inhibits ectomycorrhizal fungi in its introduced range. J Ecol 96, 777-783.

Edited by: R. P. Oliver 